\title{
Effect of Aerobic Dance on the Body Fat Distribution and Cardiovascular Endurance in Middle Aged Women
}

\section{Jaywant, P.J.}

Asst. Professor, Dept of Physiology, Grant Government Medical College \& Sir JJ Group of Hospitals, Mumbai 400008. Email: drpallavisawant@yahoo.in

\section{Abstract}

Dance aerobics is a popular means of exercise in the urban population. This study evaluates effect of Dance Aerobics on cardiovascular endurance and body fat percentage in middle aged women. To ensure uniformity in the findings, Cooper Protocol, a standardised protocol for dance aerobics was followed, ensuring optimal exercise intensity and minimal musculotendinous damage.

120 middle aged women divided in two groups were examined for $\mathrm{VO}_{2 \max }$ and body fat percentage .Group I comprised 60 women engaged in regular aerobic dance sessions, since 6 months. Group II did not engage in any exertional physical activity. Unpaired t test was used. $\mathrm{p}=$ 0.001 considered significant. Aerobic dancers exhibited i) no significant difference in $\mathrm{VO}_{2 \max }$ $(\mathrm{p}=0.00201)$ ii) lower fat percentage $(\mathrm{p}=0.01462)$, indicating aerobics is highly effective in weightloss, but effects on cardiovascular endurance are not pronounced. Increasing intensity of existing protocol to achieve increased $\mathrm{VO}_{2 \max }$ may hasten musculotendinous damage. This should be considered before an individual selects aerobic dancing as fitness activity.

\section{Keywords: Cooper Protocol, $\mathrm{VO}_{2 \max }$, Callipers}

\section{Introduction}

The aerobic dancing is a popular means of exercise regimen, especially in the urban population.Exercising to music, non requirement of costly equipments or space especially have made dance aerobics very popular in urban areas. Numerous studies carried out on aerobic dance and its effect on body. These have yielded mixed results of the aerobic dancing on various physiological parameters of the population (Kathleen \& Rockefeller, 1979; Patricia, 1987; Williford et al, 1989; Garber et al 1992; Grant et al, 2002; Lehri, and Mokha, 2006; Pantelić et al, 2007; Jakubec et al, 2008; Schiffer et al, 2008; Angioi et al, 2009; Keogh et al 2009; Leelarungrayub et al, 2011;
Hopkins et al, 1990). The difference may be due to difference in the cadence and impact of the various dance schedules (Uchechukwu, 2009). The following study considers the effect of dance aerobics on the $\mathrm{VO}_{2 \max }$ and body fat content on middle aged women. The dance schedule followed in the study was based on Cooper Protocol (Bull, 1996).

\section{Materials and Methods:}

The study was carried out after obtaining the Institutional Ethical Committee Approval. The study was carried out in two groups. Group I consisted of 60 middle aged women who practiced aerobic dance since atleast 6 months..Each session of aerobic dance 
lasted for one hour, thrice a week. Group II consisted of 60 middle aged women not engaged in any exertional physical activity. Prior to testing, required pre-test instructions were given to all volunteers and the tests were properly explained and demonstrated. The total body fat percentage (Grzonkowski et al, 1989) and $\mathrm{VO}_{2 \max }$ (McArdle et al, 2010) respectively was calculated in the two groups. The skin fold thickness was measured by skin fold calipers (Gause \& Dey, 2005) at triceps, subscapular region, suprailiac region, abdomen and thighs. The following precautions were followed while taking the measurements by the skin fold callipers:

The volunteers were asked not to eat or drink anything two hours prior to measurement of body fat. The callipers were placed on the exact site marked before. The readings taken in the first 5 seconds only were considered. The callipers were placed perpendicular to the site measured. The sum of skin folds reflected absolute or percentage changes in body fat (McArdle et al, 2010). Measurement sites for the callipers were as follows

1. Triceps: Vertical fold in the posterior midline of right upper arm, half way between the tip of shoulder and the tip of elbow; the elbow remains in an extended, relaxed position.

2. Subscapular: Oblique fold just below the bottom tip of of right scapula.

3. Iliac : Slightly oblique fold just above the iliac crest

4. Abdominal : vertical fold 1 inch to right of umbilicus
5. Thigh: vertical fold at the midpoint of right thigh.

6. Biceps : vertical fold at the midline of the right upper arm

Formula for prediction of fat from skin fold:

$\%$ body fat $=8.997+0.24658(3 \mathrm{SKF})-$

6.343 (gender) - 1.998 (race)

Where SKF $=$ sum of skin folds

Gender $=0$, female 1 , male

Race $=0$, white 1 , black

The equation was age adjusted for specific ages as the $\%$ body fat increases with age.

The sum of skin folds reflects absolute or percentage changes in body fat (Bandyapadhyay, 2005).

\begin{tabular}{lcc}
\hline Classification & Men & Women \\
\hline Essential fat & $2-4$ & $10-12$ \\
Athletes & $6-13$ & $14-20$ \\
Fit & $14-17$ & $21-24$ \\
Acceptable & $18-35$ & $25-31$ \\
Obese & 35 plus & 31 pLus \\
\hline
\end{tabular}

The $\mathrm{VO}_{2 \max }$ is the measure of cardiovascular endurance of an individual (McArdle et al, 2010). This was measured using the Queens Step Test (Chatterjee et al, 2005) - a threeminute step test (each step 16.25 inches). The post exercise recovery heart rate was calculated post each stepping cycle to a four step cadence, 'up up down down'. The women performed 22 step ups per minute, regulated by a metronome set at 88 beats per minute. The step test began after a brief demonstration and practice. At the completion of 3 minutes, pulse rate was measured for 15 seconds, after 5 to 20 secs of recovery (Uchechukwu, 2009). (ST PULSE$)$ 
Recovery Heart Rate was converted to beats per minute and calculated as.

$\mathrm{VO}_{2 \max }=65.81-\left(0.1847 \times \mathrm{ST}_{\text {PULSE }}\right)$ for women

\section{Results \& Discussion}

The results were tabulated and analysed by SPSS software. The unpaired t test was applied. $\mathrm{p}=0.001$ was considered significant.

Table 1: Comparison of aerobic dancers $\&$ working women

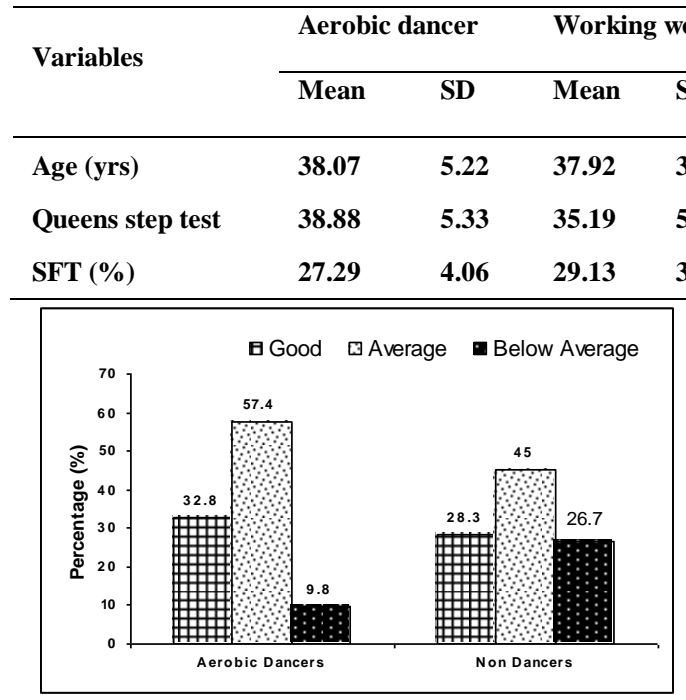

Figure 1: Comparison of Queen's Step Test of Dancers \& Non-dancers

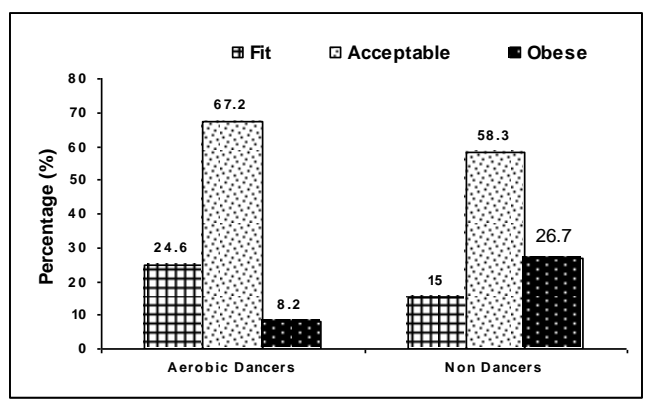

Figure 2: Comparison of Body Fat \% of Dancers \& Non-dancers

The results show that though the $\mathrm{VO}_{2 \max }$ values are higher in the dancers than the non dancers, the result is not statistically significant $(\mathrm{p}=0.00201)$ [Fig. I]. The values for the total body fat percentage however are statistically significant ( $\mathrm{p}=0.01462)$ [Fig. 2].

The vigorous dance activity increases the resting metabolism in the body cells.
Mann-Whitney Test applied

Difference is-

$\begin{array}{lll}\mathbf{- 0 . 1 4 6} & \mathbf{0 . 8 8 4} & \text { Not significant } \\ \mathbf{- 3 . 0 8 9} & \mathbf{0 . 0 0 2 0 1} & \text { Not Significant } \\ \mathbf{- 2 . 4 4 2} & \mathbf{0 . 0 1 4 6 2} & \text { Significant }\end{array}$

There is facilitation of lipid mobilisation and oxidation especially from the visceral adipose tissue (Guyton and Hall, 1996). There is probably an increase in estimated daily energy expenditure in aerobic dancers compared to working women that creates a slightly negative energy balance in aerobic dancers, causing calorie expenditure, resulting in the weight loss. This may be the cause of reduced body fat in aerobic dancers.

$\mathrm{VO}_{2 \max }$ is the measure of the cardiorespiratory endurance of the individual (McArdle et al, 2010). The slightly increased values of $\mathrm{VO}_{2 \max }$ in the aerobic dancers may be due to decreased peripheral resistance, increased cross sectional diameter of the coronary arteries, and improved tone of the ventilatory musculature (McArdle et al, 2010). Nitrous oxide released due to the shear stress may be the reason for these effects. However, for the significant change to occur in $\mathrm{VO}_{2 \max }$ the Critical Training Threshold (Astrand et al, 2003, McArdle et al, 2010). needs to be achieved. This may not be achieved during a standard Cooper Protocol Aerobic Dance session (Bull, 1996). 
Conclusion: This is a very important fact which needs to be considered before an individual considers aerobic dance as a fitness activity. If a person is aiming for just weight loss, then the dance aerobics is an ideal choice, however, if the person is aiming for improved cardiovascular status, other physical exertional activities may be considered.

\section{References}

Alekel Lee; Clasey Jody L.; Fehling, Patricia C.; Weigel Ronald M.; Boileau, Richard A.; Erdman, John W.; Stillman, Rachel 1995. Contributions of exercise, body composition, and age to bone mineral density in premenopausal women. Med. Sci. Sports Exer., 27(11): 1477-1485.

Angioi, M, Metsios, G.S., Koutedakis, Y., Wyon, M.A. 2009. Fitness in contemporary dance: a systematic review, Int. J. Sports Med., 30(7): 475-84.

Astrand, O., Rodahl, K., Dahl, H., Stromme, S. B., 2003. Textbook of work physiology: physiological basis of exercise, $4^{\text {th }}$ edition": 165- 166.

Bandyapadhyay, Amit, 2008. Queens College Step Test as an alternative to Harvard Step Test In Young Indian Women. Int. J. Sports Health Sci., year ? 15-20.

Birngum, Larry, Tommy, Boone, Beth, Huscle 2009. Cardiovascular responses to music tempo during steady state exercise. J. Exer. Physiology online 12(1): 50-57.

Bull, A. 1996. The Formal Description Of Aerobic Dance Exercise :A Corpus-Based Computational Linguistics Approach : 5 -10. Doct Thesis,University of Leeds, UK,96

Chatterjee, S., Chatterjee, P., Bandyopadhyay, A., 2005. Validity of Queen's College Step Test for estimation of maximum oxygen uptake in female students." Ind. J. Med. 121: $32-35$.

Darby, L.A., Browder, K.D., Reeves, B.D., 1995. The effects of cadence, impact, and step on physiological responses to aerobic dance exercise. Res. Quart. Exer. Sports, 22-28.

Garber, C.E, McKinney, J.S, Carleton, R.A. 1992. Is aerobic dance an effective alternative to walk-jog exercise training? The J. Exer. Phys. Fit., 32(2): 136-41.

Grant, S., Davidson, W., Aitchison, T., Wilson, J., 2002. A comparison of physiological responses and rating of perceived exertion between high-impact and low-impact aerobic dance sessions. Brit. J. Sports Med. 36(4): 276-80.

Grzonkowski, S 1989. Analysis of the results of the measurements of adipose tissue in the human body based on the study of skinfold thickness". Epidemiology, 272-282.

Grzonkowski, S, Kupść, W., Piotrowski, W., 1989. Analysis of the results of the measurements of adipose tissue in the human body based on the study of skinfold thickness." $J$. Epidem., 43(3): 272-82.

Guyton, A.C. and Hall, J.E. 1996. Textbook of Medical Physiology. 9th edition. W. B. Saunders Company, London. 80 -81.

Hopkins R, PE, Betty Murrah, M, Werner W. K. Hoeger, Ed and R. Colbert Rhodes, 1990. Effect of Low-Impact Aerobic Dance on the Functional Fitness of Elderly Women. The Gerontologist, 30(2): 189-192.

Jakubec, Aleš, Pavel, Stejskal, Liběna, K., Milan, E., Iva, ̌̌., Michal, B., Milan, P. 2008. Changes In Heart Rate Variability After A Six Month Long Aerobic Dance Or StepDance Programme In Women 40-65 Years Old: The Influence Of Different Degrees Of Adherence, Intensity And Initial Levels". GYMNICA 38(2): 35-42.

Kathleen, A., Rockefeller, Burke, E. J. 1979. Psycho-physiological analysis of an aerobic dance programme for women." British $J$. Sports Medicine, 13: 77-80.

Kelley, G., Kristi, A., Kelley, S., Zung, V. T. 2004. Aerobic Exercise and Lipids and Lipoproteins in Women: A Meta-Analysis of Randomized Controlled Trials. J. Women's Health, 13(10): 1148-1164.

Keogh, J.W., .Kilding, A., Pidgeon, P, Ashley, L, Gillis, D. 2009. Physical benefits of dancing for healthy older adults: a review. J. Ageing Physical Activity 17(4): 479-500.

Kojdab, Georg 2005. Molecular mechanisms of vascular adaptations to exercise. Physical activity as an effective antioxidant therapy?" Cardiovascular Research, 67: 187-197.

Koley, S. 2007. Association of Cardio respiratory 
Fitness, Body Composition and Blood Pressure in Collegiate Population of Amritsar, Punjab, India". The Internet Journal of Biological Anthropology, 1(1): 23-26.

Leelarungrayub, D., Saidee, K., Pothongsunun, P., Pratanaphon, S., Yankai, A., Bloomer, R.J. 2011. Six weeks of aerobic dance exercise improves blood oxidative stress status and increases interleukin-2 in previously sedentary women." J. Body Weight Movement Therapy., 15(3): 355-62.

Lehri, A. and Mokha, R, 2006. Effectiveness of Aerobic and Strength Training in Causing Weight loss and Favourable Body Composition in Females." J. Exer. Sci. and Physioth., 2: 96-99.

Mc Ardle, W., Katch, F., Katch, V. 2010. Exercise Physiology, $7^{\text {th }}$ edition: 245. 468-501 733758.568-569.820.888.

Nilsson Gause-, D., Dey, K. 2005. Percent body fat estimation from skin fold thickness in the elderly. Development of a population-based prediction equation and comparison with published equations in 75-year-olds. $J$. Nutr., Health \& Ageing, 9(1): 19-24.

Pantelić, S., Kostić, R., Mikalački, M., Ratomir Đurašković, R., Nebojša Čokorilo, N., Ivana Mladenović, I. "The effects of a recreational aerobic exercise Model on the functional abilities of women" UDC 796.035.57:058.833 Physical Education and Sport, 5(1): $19-35$.

Patricia, G.A. 1987. The effect of intensity controlled aerobic dance exercise on aerobic capacity of middle-aged, overweight women" Res. Nurs. and Health 10(6): 383-390. women: A densitometric and anthropometric evaluation. Am. J. Physical Anthropology, 53(4): 611-616.

Okura, T., Nakata, Y., Lee, D.J., Ohkawara, K. and Tanaka, K. 2005. "Effects of aerobic exercise and obesity phenotype on abdominal fat reduction in response to weight loss" International Journal of Obesity, 29: 1259-1266.

Schiffer, Thorsten, Schulte, Stefanie, Sperlich, Billy 2008. "Aerobic dance: health and fitness effects on Middle-aged premenopausal women". Journal of Exercise Physiologyonline(JEPonline), 11 (4): 25-33.

Uchechukwu, D., 2009. Post-exercise heart rate recovery: an index of cardiovascular fitness". J. Exer. Physiol., 12(1): 10-22.

Vajda I, Mészáros J, Mészáros Z, Prókai A, Sziva A, Photiou A, Zsidegh, 2007. Effects of 3 hours a week of physical activity on body fat and cardio-respiratory parameters in obese boys. Sep.94(3): 191-8.

Vajda, I. 2007. Effects of 3 hours a week of physical activity on body fat and cardiorespiratory parameters in obese boys. "Acta Physiologica Hungarica, 94(3): 191-198.

Varghese, M.A., Saha, P.N., Atreya, N., 1995. Aerobic capacity of urban women homemakers in Bombay." Ergonomics. Sep; 38(9): $1877-83$.

Williford, T. H. N, Scharff-Olson, M., Blessing, D. L. 1989. The physiological effects of aerobic dance. A review. J. Sports Medicine, Dec; 8(6): 335-45.

Satwanti, P. Singh, I.P., Bharadwaj, H. 1980. Fat distribution in lean and obese young Indian 